\title{
Article \\ Facile Fabrication of Hybrid Carbon Nanotube Sensors by Laser Direct Transfer
}

\author{
Anca F. Bonciu ${ }^{1,2} \mathbb{D}$, Mihaela Filipescu ${ }^{1}\left(\mathbb{D}\right.$, Stefan I. Voicu ${ }^{3,4}\left(\mathbb{D}\right.$, Thomas Lippert ${ }^{5,6} \mathbb{C}^{\mathbb{D}}$ \\ and Alexandra Palla-Papavlu 1,*(D) \\ 1 Lasers Department, National Institute for Lasers, Plasma and Radiation Physics, Atomistilor 409, \\ 077125 Magurele, Romania; anca.bonciu@inflpr.ro (A.F.B.); mihaela.filipescu@inflpr.ro (M.F.) \\ 2 Faculty of Physics, University of Bucharest, Atomistilor 409, 077125 Magurele, Romania \\ 3 Department of Analytical and Environmental Chemistry, University Politechnica of Bucharest, \\ 1-7 Gh. Polizu Str., 011061 Bucharest, Romania; svoicu@gmail.com \\ 4 Advanced Polymer Materials Group, University Politehnica of Bucharest, 1-7 Gh. Polizu Str., \\ 011061 Bucharest, Romania \\ 5 Laboratory of Inorganic Chemistry, Department of Chemistry and Applied Biosciences, ETH Zurich, \\ 8093 Zurich, Switzerland; thomas.lippert@psi.ch \\ 6 Laboratory of Multiscale Materials Experiments, Paul Scherrer Institute, 5232 Villigen, Switzerland \\ * Correspondence: Alexandra.papavlu@inflpr.ro
}

check for updates

Citation: Bonciu, A.F.; Filipescu, M.; Voicu, S.I.; Lippert, T.; Palla-Papavlu, A. Facile Fabrication of Hybrid Carbon Nanotube Sensors by Laser Direct Transfer. Nanomaterials 2021, 11, 2604. https://doi.org/10.3390/ nano11102604

Academic Editor: Johannes Heitz

Received: 13 September 2021

Accepted: 1 October 2021

Published: 3 October 2021

Publisher's Note: MDPI stays neutral with regard to jurisdictional claims in published maps and institutional affiliations.

Copyright: (c) 2021 by the authors. Licensee MDPI, Basel, Switzerland. This article is an open access article distributed under the terms and conditions of the Creative Commons Attribution (CC BY) license (https:// creativecommons.org/licenses/by/ $4.0 /)$.

\begin{abstract}
Ammonia is one of the most frequently produced chemicals in the world, and thus, reliable measurements of different $\mathrm{NH}_{3}$ concentrations are critical for a variety of industries, among which are the agricultural and healthcare sectors. The currently available technologies for the detection of $\mathrm{NH}_{3}$ provide accurate identification; however, they are limited by size, portability, and fabrication cost. Therefore, in this work, we report the laser-induced forward transfer (LIFT) of single-walled carbon nanotubes (SWCNTs) decorated with tin oxide nanoparticles $\left(\mathrm{SnO}_{2} \mathrm{NPs}\right)$, which act as sensitive materials in chemiresistive $\mathrm{NH}_{3}$ sensors. We demonstrate that the LIFT-fabricated sensors can detect $\mathrm{NH}_{3}$ at room temperature and have a response time of $13 \mathrm{~s}$ (for $25 \mathrm{ppm} \mathrm{NH}$ ). In addition, the laser-fabricated sensors are fully reversible when exposed to multiple cycles of $\mathrm{NH}_{3}$ and have an excellent theoretical limit of detection of $24 \mathrm{ppt}$.
\end{abstract}

Keywords: gas sensor; ammonia detection; hybrid; LIFT; laser; nanocomposite; SWCNT; $\mathrm{SnO}_{2}$

\section{Introduction}

Ammonia $\left(\mathrm{NH}_{3}\right)$ is one of the most frequently produced industrial chemicals in the United States and China [1]. $\mathrm{NH}_{3}$ is extensively used in various industrial applications, i.e., production of fertilizers, plastics, dyes, etc. Exposure to high concentrations of ammonia in air causes bronchiolar and alveolar edema, while the inhalation of lower concentrations can cause coughing, nose, and throat irritation [2]. According to the National Institute for Occupational Safety and Health (NIOSH), the acceptable exposure limit is 25 ppm for $8 \mathrm{~h}$ and 35 ppm for 15 min exposure.

Therefore, detection of ammonia requires efficient devices with several key characteristics, i.e., sensitivity, the minimum concentration of target gases they can detect, response speed, reversibility, energy consumption, and fabrication costs [3].

For the last 50 years, the field of sensors has been dominated by metal oxide semiconductor sensors based on $\mathrm{SnO}_{2}, \mathrm{In}_{2} \mathrm{O}_{3}, \mathrm{ZnO}_{2}, \mathrm{WO}_{3}$, etc. [4]. This type of sensor has numerous advantages in terms of raw material costs, high sensitivity, etc. However, their main disadvantage is that they have to be operated at higher temperatures, (e.g., $\mathrm{SnO}_{2}$ at $500{ }^{\circ} \mathrm{C}$ ), which makes difficult their application on flexible substrates [5].

The field of sensors is far from developed, and since the pioneering work of Dai et al. [6], in which the first examples of single-walled carbon nanotube (SWCNT) chemical sensors were reported, sensors based on CNT have gained great interest. Resistive SWCNT-based 
sensors are low-power devices that are ideal for direct electrical detection [7]. SWCNTs have been proven effective for the detection of common organic vapors, [8] oxidizing vapors such as $\mathrm{Cl}_{2}$ or $\mathrm{NO}_{2}$, [9] and even trinitrotoluene [10] and chemical warfare agents [11]. The main drawbacks for the application of SWCNT in sensors are the high price and the necessity to find techniques to deposit them on the active area of a resistive sensor with high enough conductivity [12].

Although there are numerous examples of sensors based on pristine CNTs, different reports available in the literature [13] associate an increased sensor response and sensitivity toward different analytes to residual metal catalysts or particles from the production process. Thus, hybrid carbon-based sensing materials can be developed by intentionally decorating or doping carbon nanotubes with metal nanoparticles in order to produce a stronger and specific response toward the analytes of interest [14].

Therefore, in this work, we focused on an easy and straightforward sensor device fabrication strategy that relies on laser printing of the sensing materials by laser-induced forward transfer (LIFT). LIFT is a solvent-free and versatile fabrication method, which has already been applied for device fabrication $[15,16]$. The basic principle of LIFT relies on shaping and projecting a laser beam onto a donor substrate coated with the material to be transferred. The donor substrate coated with the material to be transferred is then placed parallel and at a controllable distance to a receiving substrate, and the entire system is moved with respect to the fixed laser beam so that it is possible to "write" arbitrary patterns. Laser transfer of material takes place when a single laser pulse is fired. From the large donor substrate, a selective transfer of only a small part defined by the laser spot can be achieved, without any additional photolithography step. Using this configuration, the laser interacts with the material to be transferred and only insensitive materials such as metals or ceramics can be transferred. In order to transfer materials that can be damaged by the laser beam (generally proteins or polymers), the LIFT process needs to be improved by adding an intermediate layer between the donor substrate and the material to be transferred with the role to protect the material to be transferred from the applied laser light and generated heat.

Few examples of carbon nanotube transfers by LIFT have been reported previously; for example, in [16], we have proved that it is possible to transfer SWCNT by LIFT with the goal of fabricating chemiresistive sensors that detect ammonia in the ppm range. Furthermore, in [17], the authors demonstrated the possibility to print polymer-multiwalled carbon nanotube composites by LIFT, while in [18], the authors demonstrated the transfer of SWCNTs and SWCNTs embedded in a polymer matrix by using a blister to mechanically deform the donor layer. Moreover, in [19], the authors presented the possibility to LIFT and decorate multiwalled carbon nanotubes with gold-palladium nanoparticles and demonstrated the adsorption characteristics toward hydrogen.

Therefore, in this study, we focused on transferring hybrid SWCNT, i.e., decorated with tin oxide nanoparticles $\left(\mathrm{SWCNT@SnO} \mathrm{O}_{2}\right)$ with the purpose of obtaining improved and reproducible resistive sensors. We report, for the first time, the fabrication of resistive sensors by laser-induced forward transfer of hybrid nanocomposites, i.e., SWCNT@SnO 2 with an excellent detection limit toward ammonia in the low ppt range.

\section{Materials and Methods}

\subsection{Preparation of the Materials to Be Transferred-Donor Fabrication}

The materials to be transferred by laser-induced forward transfer were single-walled carbon nanotubes (SWCNT, HiPco) purchased from Nanointegris, and hybrid nanocomposites based on SWCNT and $\mathrm{SnO}_{2}$ nanoparticles were purchased from Alfa Aesar. We chose SWCNT over MWCNT, taking into account gas-nanostructure interactions, and the work of Picaud et al. [20], in which the authors have reported that for the same amount of $\mathrm{NH}_{3}$ molecules adsorbed on the two types of carbon nanotubes, the SWCNTs appear to have the best sensitivity to $\mathrm{NH}_{3}$. 
The SWCNT@SnO $\mathrm{S}_{2}$ dispersions were realized at a 1:14 SWCNT: $\mathrm{SnO}_{2}$ ratio. Briefly, the SWCNTs were used as received, without any additional purification step. Dispersions of SWCNTs in water were realized by suspending $10 \mathrm{mg}$ CNT powder in $15 \mathrm{~mL}$ water containing $100 \mathrm{mg}$ Triton $\mathrm{X}$. The $\mathrm{SnO}_{2}$ nanoparticles used in this work had a nominal particle size of $10-15 \mathrm{~nm}$ and were dispersed in a colloidal solution at a concentration of $14 \mathrm{wt} . \%$ in water. The dispersion was a bath sonicated for $40 \mathrm{~min}$.

The hybrid SWCNT@SnO 2 nanocomposites were prepared by dispersing the HiPco SWCNT in the $\mathrm{SnO}_{2}$ NP solutions by ultrasonic vibration for about $2 \mathrm{~h}$ to obtain the well-mixed suspensions.

The preparation of the TP layer, the SWCNT, and hybrid SWCNT@SnO 2 layers was carried out following the procedure described schematically in Figure 1.

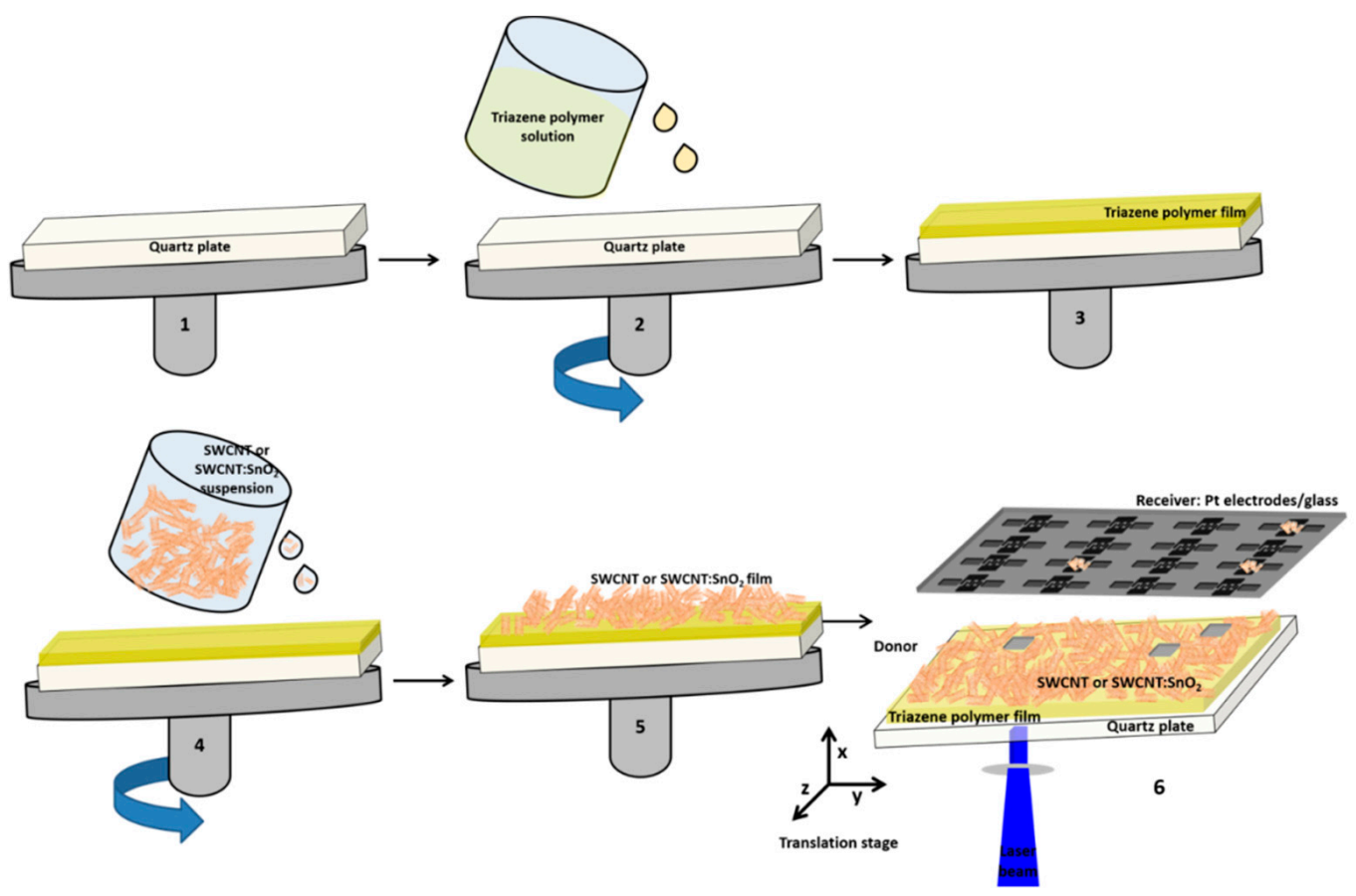

Figure 1. Scheme of the LIFT setup: step 1-5 fabrication of the donor substrate by spin coating, and step 6 transfer by LIFT of the donor material (SWCNT@SnO 2 ) onto the receiver substrate (glass plate with Pt electrodes). Step 1: The donor plate was placed in the spin coater. Step 2 and 3: The quartz plate was coated with a thin film of the triazene polymer (TP). Step 4 and 5: The SWCNT@SnO ${ }_{2}$ suspension was spin-coated onto the TP/quart plate. Step 6: The donor and receiver were placed onto an $x y z$ translation stage. The laser beam impinges through the transparent quartz plate, vaporized the TP, which mechanically pushed forward a small portion of the SWCNT@SnO 2 film onto the glass plate with Pt electrodes.

In order to prepare the donor films for the LIFT experiments, a preliminary step of coating fused silica plates with a photosensitive polymer, i.e., a triazene polymer (TP), was carried out. The specific triazene polymer was synthesized, following the procedure published previously [21]. The triazene polymer was deposited by spin coating from a $2 \% \mathrm{wt}$ solution of chlorobenzene and cyclohexanone $(1: 1 w / w)$. The TP-containing solution was dispensed onto the substrate through a $0.45 \mu \mathrm{m}$ filter. Spinning was carried out for $60 \mathrm{~s}$ at a speed of $2000 \mathrm{rpm}$ with a ramp of $1000 \mathrm{rpm} / \mathrm{s}$. The films were dried after deposition for $2 \mathrm{~h}$ at $50{ }^{\circ} \mathrm{C}$. Films with a thickness of $150 \mathrm{~nm}$ were obtained with this procedure.

The SWCNT and SWCNT@SnO 2 layers were fabricated by spin coating the SWCNT and SWCNT@SnO ${ }_{2}$ dispersions (different experiments) onto TP-coated fused silica plates under different conditions, i.e., rotation speed 1500-2500, a ramp of 1000-2000 rpm, and spin-coating duration of 30 and $60 \mathrm{~s}$. Once the final donor layers were obtained, a postheating step $\left(60^{\circ} \mathrm{C}\right.$ for $\left.4 \mathrm{~h}\right)$ was applied to remove the residual solvent from the film. 


\subsection{LIFT}

The LIFT setup used in this work has been detailed in our previous works $[5,16]$ and it consists of a pulsed $\mathrm{XeCl}$ laser (308 nm emission wavelength, $30 \mathrm{~ns}$ pulse length, $1 \mathrm{~Hz}$ repetition rate), which is guided and imaged with an optical system at the quartz substrate-TP layer interface, and as a result of the rapid increase in pressure at the quartzTP interface, a part of the donor layer (SWCNT or SWCNT@SnO ${ }_{2}$ ) is transferred (further named pixel) onto the receiving substrate. A computer-controlled $x y z$ translation stage allowed the displacement of both donor and receiving substrates with respect to the laser beam. The donor and the receiving substrates were kept in contact. All experiments were carried out under ambient pressure at temperatures close to room temperature.

As receiver substrates, we used both glass coverslips cut into $25 \times 25 \times 1 \mathrm{~mm}^{3}$ pieces for the post-characterization of the transferred pixels, as well as interdigitated (IDT) electrodes. The IDT electrodes have a similar structure to the commercial sensors (Microsens gas sensor, MSGS 3000). Briefly, the IDT electrodes were fabricated by sputtering a $20 \mathrm{~nm}$ chromium layer, followed by a $100 \mathrm{~nm}$ platinum layer on top onto a borax glass substrate [5].

In order to obtain a stable sensor response, the LIFT-printed sensors were subjected to a heating treatment, similar to the commercial sensors. The LIFT-printed sensors were heated for $6 \mathrm{~h}$ at $150{ }^{\circ} \mathrm{C}$, followed by $6 \mathrm{~h}$ at $100{ }^{\circ} \mathrm{C}$ in a stream of $1 \mathrm{~L} / \mathrm{min}$ of synthetic air (SA) containing $20 \% \mathrm{O}_{2}$ and $80 \% \mathrm{~N}_{2}$.

The transferred SWCNT and SWCNT@SnO 2 pixels, as well as the donor films prior to ablation, were investigated by optical microscopy. The images were acquired with an Olympus SZH 10 Research Stereomicroscope, coupled with a Stingray F145C CCD camera.

The distribution of the SWCNT and SWCNT@SnO 2 prior to and after their deposition by LIFT was investigated by scanning electron microscopy (SEM). The images were obtained from top-view SEM and were acquired with a Zeiss Supra VP55 FE-SEM apparatus operating at a voltage of $5 \mathrm{kV}$ and using an in-lens detector.

\subsection{Sensor Testing Setup}

The functionality of the LIFT-printed SWCNT and hybrid SWCNT@SnO ${ }_{2}$-based sensors was assessed in a setup that has been described previously in [5]. Briefly, the sensor testing setup consisted of a sensor-testing chamber provided with a constant gas supply, where the sensors were mounted on an alumina block and were contacted electrically by two metal clamps, on the side pressing graphite rode onto the Pt-electrodes reaching a total contact resistance of less than $50 \Omega$. Graphite rods were needed to prevent the Pt-electrodes to be scratched off [5]. The resistance measurements were acquired by a computer-controlled (LabView) setup using a Keithley 2400 source meter and Keithley 2000 multimeter. The main gas supply was dry $\mathrm{N}_{2}$ (both as balance and purging gas) with a standard gas flow of $5 \mathrm{~L} / \mathrm{min} \mathrm{SA}$.

In order to test the LIFT-printed SWCNT and hybrid SWCNT@SnO 2 -based sensors for their ability to detect $\mathrm{NH}_{3}$, defined concentrations of $\mathrm{NH}_{3}$ were mixed in a balloon from Carl Roth and added in small quantities to the main gas stream. This mixture was added with a low flow rate $(0.01$ to $0.1 \mathrm{~L} / \mathrm{min})$ to the main gas flow and analyte concentrations in the ppm range were thus achieved [5].

\section{Results and Discussion}

\subsection{LIFT Printing}

The gas-sensing mechanism of the sensors is dependent upon multiple factors, including the surface of the active material; therefore, the analysis of the donor films morphology was conducted first. Following our donor fabrication strategy shown in Figure 1, we could spin coat randomly oriented SWCNTs arranged in curly bundles (see Figure 2a). In addition, several $\mu \mathrm{m}$ long carbon nanotube bundles with diameters in the range 30 to $70 \mathrm{~nm}$, and $\mathrm{SnO}_{2} \mathrm{NP}$, which agglomerate in clusters, with 10 to $15 \mathrm{~nm}$ dimensions, anchored to the SWCNT surface in the hybrid donor materials, which can be seen in the SEM images shown 
in Figure $2 b$. The $\mathrm{SnO}_{2}$ NPs are regularly distributed on the SWCNT, as shown in Figure 2b. However, in some areas, the $\mathrm{SnO}_{2}$ NPs are specifically agglomerated at points where the carbon nanotubes have a close bond, which has also been seen in our previous work [22], where the NPs agglomerated at defect points onto the surface of carbon nanowalls.
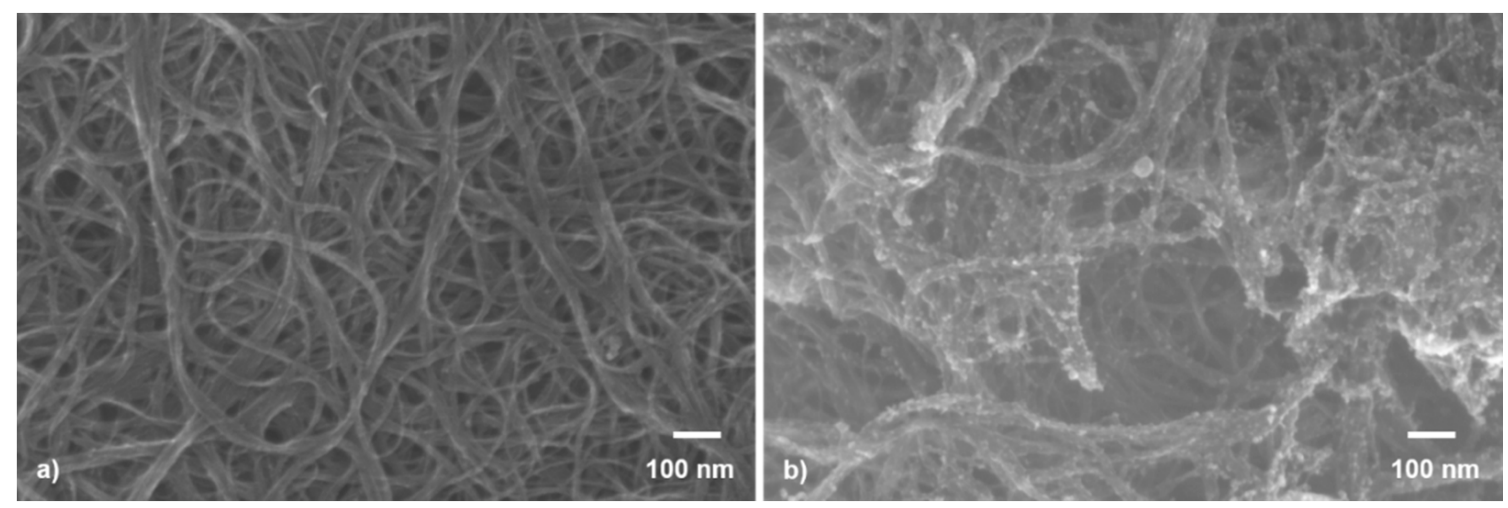

Figure 2. Representative SEM images of (a) SWCNT and (b) SWCNT@SnO 2 donors, as fabricated prior to laser transfer.

The transfer of pixels in a controlled manner, and insight on the morphological properties of the LIFT-printed single-walled carbon nanotubes and hybrid SWCNT@SnO ${ }_{2}$ are essential in applications aimed at practical devices. Once pixel deposition is possible, and controlled printing and regular pixel deposition can be achieved. In our previous work [16], we have investigated different LIFT process parameters, i.e., the TP thickness and the laser fluence applied for the transfer in order to obtain regular SWCNT patterns. Furthermore, in order to prove that LIFT is a suitable technique to be used for device fabrication, SWCNTs were transferred onto Pt electrodes, and concentrations as low as $50 \mathrm{ppm}$ of ammonia were detected. However, more work is needed to optimize the process and also to obtain better sensor response, i.e., for consistent monitoring of acceptable concentrations of $\mathrm{NH}_{3}$.

Here, we show that it is possible to transfer regular $\mathrm{SWCNT@SnO}_{2}$ with the help of a $150 \mathrm{~nm}$ thick TP DRL layer (see Figure 3). Transferring SWCNT@SnO ${ }_{2}$ by LIFT is possible, leading to sharp pixels; the best transfer is achieved with a laser fluence of $300 \mathrm{~mJ} / \mathrm{cm}^{2}$ (similar to the transfer of bare SWCNTs at $250 \mathrm{~mJ} / \mathrm{cm}^{2}$ in [16]). The overall appearance of the pixel is more "microporous" than homogeneous. Additionally, the transfer fluence of $700 \mathrm{~mJ} / \mathrm{cm}^{2}$ is comparably high and for lower fluence, no complete layer transfer is achieved. As it can be seen, reproducible transfers with an intermediate $150 \mathrm{~nm}$ thick TP layer and a laser fluence of $300 \mathrm{~mJ} / \mathrm{cm}^{2}$ are achievable.

In addition, pixels were transferred at $300 \mathrm{~mJ} / \mathrm{cm}^{2}$ laser fluence onto sensor-like pads, and their electrical characteristics and sensing abilities toward ammonia were tested further. The electrode design and an image of a LIFT-printed sensor-like pad are shown in Figure 4.

The transfers onto the IDT structure do not show significant differences from the transfers onto the glass part. An example of a $\mathrm{SWCNT@SnO}{ }_{2}$ pixel transferred onto a sensorlike pad is shown in Figure 4. After the transfer, the as-fabricated sensors were conditioned as described above in order to cure the transferred material. During LIFT, the high velocities generated (around $200 \mathrm{~m} / \mathrm{s}$ ) [16] lead to firm electrical contact between the electrodes and pixels, allowing better draining of the injected carriers through the electrodes.

These data show that LIFT transfers onto different substrate materials work very well. Transferring onto the IDTs with a structure height comparable to the film thickness shows a similar behavior as the transfers on the even surfaces. Even transfers of $\mathrm{SWCNT@SnO}_{2}$ pixels with a film thickness smaller than the IDTs structure height proved to be possible. 


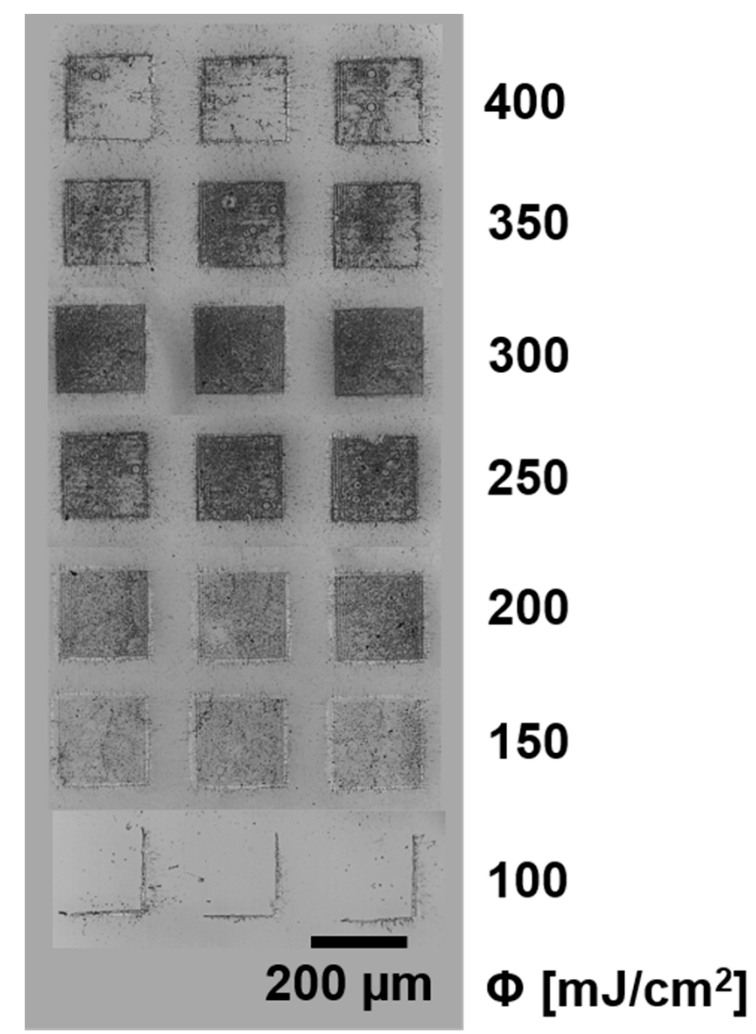

Figure 3. SWCNT@SnO 2 microarray, transferred by LIFT by keeping the donor and receiver substrates in contact.
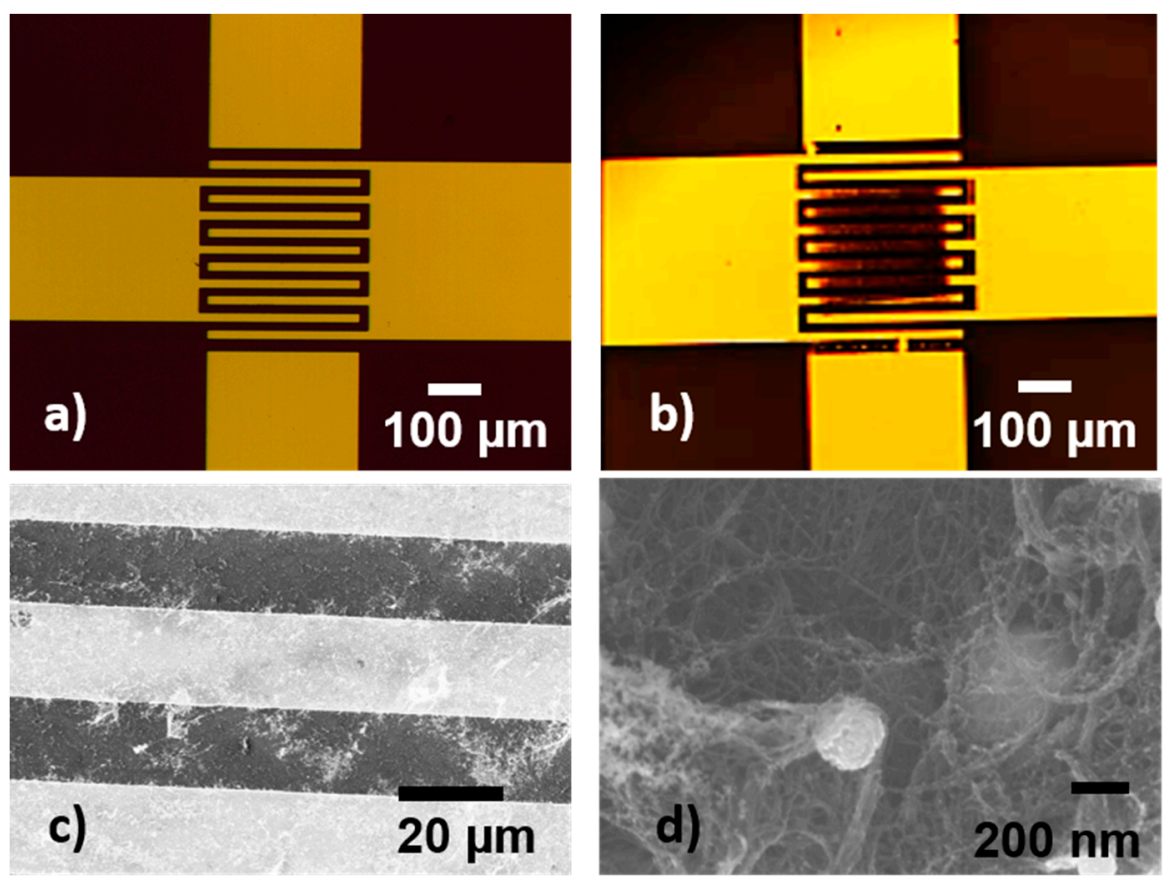

Figure 4. Optical microscopy images of (a) the interdigital electrodes and (b) a $\mathrm{SWCNT} @ S n O_{2}$ pixel printed onto the metal electrodes; (c) SEM image of SWCNT@SnO 2 pixel transferred by LIFT at $300 \mathrm{~mJ} / \mathrm{cm}^{2}$ laser fluence onto the sensor IDTs, and (d) SEM image that was taken at a higher magnification of a SWCNT@SnO 2 pixel transferred by LIFT at $300 \mathrm{~mJ} / \mathrm{cm}^{2}$ laser fluence onto the sensor IDTs, where the $\mathrm{SnO}_{2}$ nanoparticles decorating the SWCNTs can be seen. 


\subsection{Sensor Tests}

The scope of this study is to demonstrate the fabrication of proof-of-concept sensors by directly printing the active materials in the sensors, i.e., the hybrid SWCNT@SnO ${ }_{2}$ nanocomposite via laser-induced forward transfer. Here, we focused on investigating the functionality of the laser-printed active materials onto sensor structures by evaluating their potential to detect small amounts of ammonia at temperatures close to room temperature in dry nitrogen. The fabrication of sensors that operate at a temperature close to room temperature simplifies the sensor design and, in addition, allows for the elimination of the heating elements, which, in turn, offers low-power consumption devices. Furthermore, we chose ammonia, as it represents a well-known toxic pollutant and biological signaling molecule [2].

The first step was to stabilize both the SWCNT and $\mathrm{SWCNT} @ \mathrm{SnO}_{2}$ sensors under $\mathrm{N}_{2}$. This was achieved by exposure for $1 \mathrm{~h}$ in order to obtain a flat baseline. The baseline resistance (two-point electrical measurement) was measured in a dry $\mathrm{N}_{2}$ stream, at room temperature, and for both SWCNT and SWCNT@SnO 2 sensors, is typically between 2 and $15 \mathrm{kOhms}$, a resistance range very applicable for sensors and much lower than the Megaohm range found for sensors with standard SWCNT [9]. In addition, during the measurements, the temperature T was continuously measured for the SWCNT and SWCNT@SnO $2\left(\mathrm{~T}=25 \pm 2{ }^{\circ} \mathrm{C}\right)$.

Real-time measurement of an SWNCT-printed sensor to $25 \mathrm{ppm} \mathrm{NH}_{3}$ is shown in Figure 5a. The first observation that can be made is that after exposure to $\mathrm{NH}_{3}$, the resistance of the SWCNT sensors is characterized by a steep increase in a short time, and when the analyte is removed, by a slower decrease. This shows a p-type response of the SWCNTs to $\mathrm{NH}_{3}$, i.e., after exposure to $\mathrm{NH}_{3}$, the resistance of the sensors increases from approx. $6.5 \mathrm{k} \Omega$ to $9 \mathrm{k} \Omega$ (Figure 5a). This effect has been seen previously [7,9] in SWCNTs exposed to reducing molecules. Briefly, when the surface of the SWCNTs is exposed to the reducing $\mathrm{NH}_{3}$ molecules, the accumulation region is reduced, yielding a decrease of the hole current, i.e., an increase of the resistance, shown by the SWCNT sensors printed by LIFT.

In order to fabricate high-performance sensors, a prerequisite is their high reversibility in response when exposed to multiple cycles of the analyte of interest. The response of SWCNT printed by LIFT is partially reversible at the applied $\mathrm{NH}_{3}$ concentration of $25 \mathrm{ppm}$, demonstrating a quasi-dosimetric characteristic of the sensors.

Although we could have applied different remedies to achieve full reversibility, i.e., heating or UV exposure of the SWCNT sensors, we noticed that these treatments led to a high baseline noise, and therefore, we looked into the direction of noncovalent SWCNT functionalization by decorating the SWCNTs with metal oxide nanoparticles $\left(\mathrm{SnO}_{2}\right)$. In particular, the strategy of introducing active sites with strong affinities has been followed previously in order to improve sensor sensitivity [23,24].

In addition, at first, the decoration of the SWCNTs with n-type NPs might appear striking, due to the fact that the two opposing mechanisms may cancel each other, thus

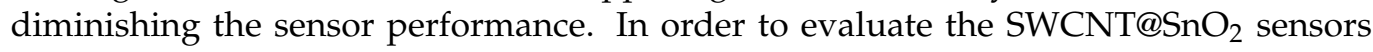
fabricated by LIFT for their ability to detect $\mathrm{NH}_{3}$ molecules, we tested them against different concentrations, i.e., in the range $1-25 \mathrm{ppm}$. We noticed that in contrast to the laser-printed SWCNT sensors, the resistance of the SWCNT@SnO 2 sensor after exposure to $\mathrm{NH}_{3}$ immediately decreases and gradually approaches a steady-state over a period of $\sim 2 \mathrm{~min}$, thus showing an n-type response to $\mathrm{NH}_{3}$. Therefore, it is safe to assume that the overall characteristic of the $\mathrm{SWCNT@SnO} 2$ sensors is determined by the properties of the $\mathrm{SnO}_{2} \mathrm{NPs}$, and the SWCNTs contribute little to the sensor response. This claim is supported also by the SEM image shown in Figure 2b, in which it can be seen that most of the $\mathrm{SnO}_{2} \mathrm{NPs}$ are in contact with each other. 


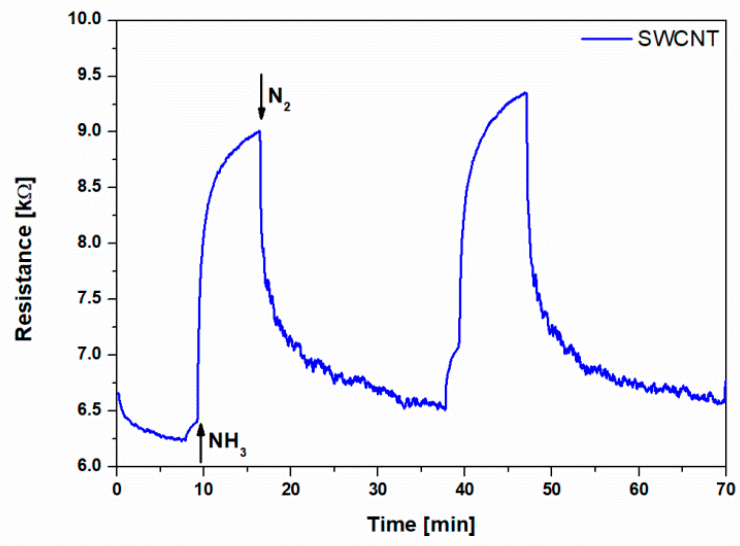

(a)

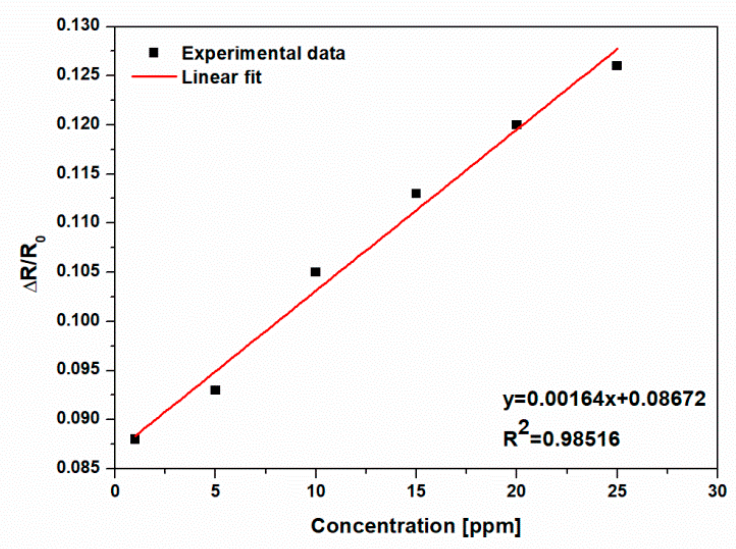

(c)

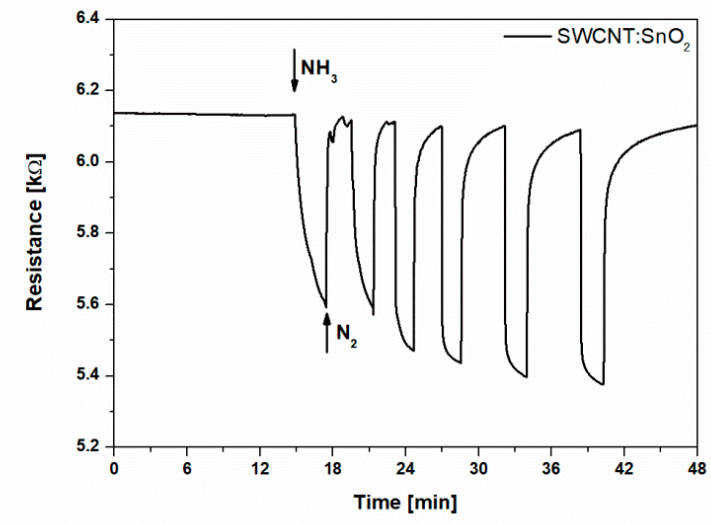

(b)

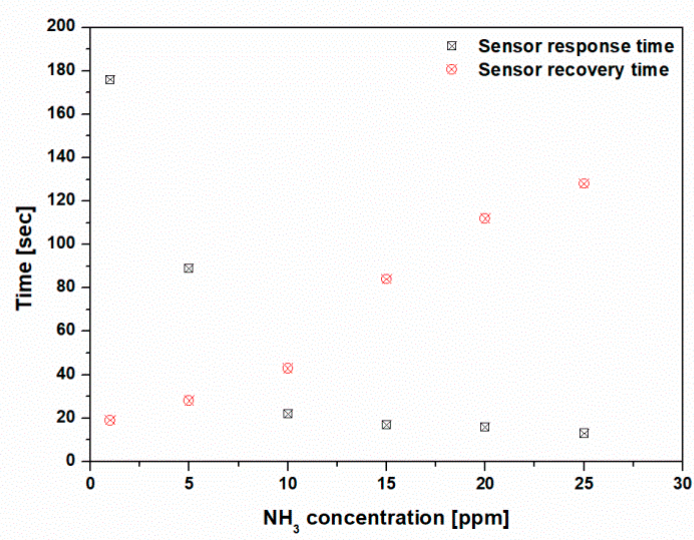

(d)

Figure 5. (a) Real-time measurements of an SWCNT sensor printed by LIFT collected for 25 ppm of $\mathrm{NH}_{3}$; (b) real-time measurements of a SWCNT@SnO $\mathrm{Sn}_{2}$ sensor printed by LIFT collected for different concentrations (1-25 ppm) of $\mathrm{NH}_{3}$; (c) SWCNT@SnO $\mathrm{S}_{2}$ sensor response as a function of $\mathrm{NH}_{3}$ concentration at room temperature in air, depicting a good linear relation; (d) response and recovery times for the $\mathrm{SWCNT@SnO}{ }_{2}$ sensor printed by LIFT exposed to different concentrations of $\mathrm{NH}_{3}(1-25 \mathrm{ppm})$.

Although the exact mechanism of the hybrid sensor response is not known, we hypothesize that the better sensor response toward $\mathrm{NH}_{3}$ analyte of the SWCNT@SnO 2 sensors, as compared with the SWCNT sensors, could be attributed to a number of factors, i.e., the enhancement of the surface area accessible to the ammonia molecules, and possibly to the formation of $\mathrm{p}-\mathrm{n}$ junctions between the semiconducting metal oxide NP and the CNT bundles. In the literature, there are many studies focused on the gas sensing mechanism in n-type semiconducting metal oxide nanoparticles and p-type carbon nanotubes, where these materials are combined to form $\mathrm{p}-\mathrm{n}$ junctions. The case of $\mathrm{p}-\mathrm{n}$ junctions between p-type SWCNTs and n-type semiconductor NP presented on hybrid SWCNT@NPs [25], however, a clear understanding of the mechanisms leading to gas sensing has not yet been reached [26].

Additional experimental and theoretical studies are needed to fully understand the interaction of the hybrid SWCNT@SnO $\mathrm{S}_{2}$ system with ammonia, to identify the hybrid sensor response as a function of the applied temperature, as well as to determine the dominant material for different $\mathrm{SnO}_{2} \mathrm{NP}$ coverage.

In addition, the $\mathrm{SWCNT@SnO} 2$ sensor response is reproducible over multiple analyte $/ \mathrm{N}_{2}$ exposure cycles, and, more importantly, the signal recovered to the original baseline value upon removal of the $\mathrm{NH}_{3}$ (Figure $5 \mathrm{~b}$ ), thus demonstrating a sensor behavior. 
In order to evaluate the performance of our printed sensors, we investigated several key factors: (i) the sensor response to ammonia, which is defined as $\Delta R / R_{0}=\left(R_{g}-R_{0}\right) / R_{0}$, where $\mathrm{R}_{\mathrm{g}}$ is the resistance upon $\mathrm{NH}_{3}$ exposure, and $\mathrm{R}_{0}$ the baseline resistance before exposure to $\mathrm{NH}_{3}$; (ii) the response and recovery times, which are defined as the times for the sensor to reach $90 \%$ of its maximum and to recover $10 \%$ of its peak value upon exposure to a given concentration of $\mathrm{NH}_{3}$.

Although both SWCNT and SWCNT@SnO ${ }_{2}$ sensors display a resistivity change, both the response and recovery appear to be much slower in the case of SWCNT with respect to the hybrid nanocomposite $\mathrm{SWCNT} @ \mathrm{SnO}_{2}$ sensors. In order to obtain quantitative correlations between the changes in the sensor responses as a function of $\mathrm{NH}_{3}$ concentration, we carried out concentration-dependent investigations. An excellent linear sensor response as a function of the tested $\mathrm{NH}_{3}$ concentrations (1-25 ppm) is depicted in Figure $5 \mathrm{c}$, with $\mathrm{R}^{2}=0.98$.

Furthermore, due to the limitations of our experimental setup, concentrations as low as $1 \mathrm{ppm}$ could be detected in dry nitrogen without any external aid such as thermal or photoirradiation (see Figure $5 b$ ). Therefore, we calculated the theoretical detection limit (LOD) (additional information can be found in Supplementary Information), as previously reported [11], from the signal/noise ratio.

The slope (0.00164) was obtained from the calibration curve of the sensor response in Figure 5c. For the LIFT-printed SWCNT@SnO ${ }_{2}$ sensors, we obtained a LOD = 23.93 ppt, which is among the lowest LOD value reported by other chemiresistive sensors based on hybrid carbon nanotubes and tin oxide nanoparticles [27]. Even more, this LOD is two orders of magnitude lower than the LOD of a single tin oxide nanowire [28].

For 1 ppm of ammonia, the response and recovery times of the $\mathrm{SWCNT@SnO}_{2}$ sensor are $176 \mathrm{~s}$ and $19 \mathrm{~s}$, respectively (see Figure $5 \mathrm{~d}$ ). These values are among the best reported in the literature (see Table 1). By increasing ammonia concentration, i.e., to $25 \mathrm{ppm}$, the response time decreases to $13 \mathrm{~s}$, while the recovery time increases moderately to $123 \mathrm{~s}$, which is still better than most in the literature (see Table 1).

Table 1. Summarized sensor parameters for different works, as compared with the SWNT@SnO 2 sensors fabricated by LIFT.

\begin{tabular}{|c|c|c|c|c|c|c|}
\hline Sensing Material & $\begin{array}{c}\text { Operating } \\
\text { Temperature }\end{array}$ & $\begin{array}{c}\text { Concentration } \\
(\mathrm{ppm})\end{array}$ & $\begin{array}{c}\text { Sensor } \\
\text { Response (\%) }\end{array}$ & Response Time & Recovery Time & Ref. \\
\hline SWCNT@SnO & RT & 25 & 0.126 & $13 \mathrm{~s}$ & $123 \mathrm{~s}$ & This work \\
\hline $\begin{array}{c}\mathrm{SnO}_{2}+ \\
15 \% \mathrm{MWCNT}\end{array}$ & RT & 200 & 0.27 & $<5 \mathrm{~min}$ & $<5 \mathrm{~min}$ & [29] \\
\hline $\mathrm{SnO}_{\mathrm{X}}-\mathrm{SWNT}$ & $200^{\circ} \mathrm{C}$ & 1000 & 0.81 & $2.02 \mathrm{~min}$ & $3.14 \mathrm{~min}$ & {$[30]$} \\
\hline $\begin{array}{c}\mathrm{SnO}_{2}+1 \% \mathrm{wt} \\
\mathrm{MWCNT}\end{array}$ & 220 & 60 & 0.19 & $>100 \mathrm{~s}$ & $>100 \mathrm{~s}$ & [31] \\
\hline Cellulose fiber & RT & $0.2-1000$ & 40 (80 ppm) & $186 \mathrm{~s}$ & $163 \mathrm{~s}$ & [32] \\
\hline $\mathrm{SnO}_{2}-\mathrm{Pt}$ & $230^{\circ} \mathrm{C}$ & 1 & - & $1 \mathrm{~s}$ & $59 \mathrm{~s}$ & [33] \\
\hline $\mathrm{Co}_{3} \mathrm{O}_{4}$ nanosheets & $\mathrm{RT}$ & $0.2-100$ & - & $9 \mathrm{~s}$ & $134 \mathrm{~s}$ & {$[34]$} \\
\hline $\mathrm{TiO}_{2} / \mathrm{Ti}_{3} \mathrm{C}_{2} \mathrm{~T}_{\mathrm{x}}$ & RT & $0.5-10$ & 3.1 (10 ppm) & $33 \mathrm{~s}$ & $277 \mathrm{~s}$ & [35] \\
\hline $\mathrm{CuBr}$ & RT & 5 ppb-5 ppm & $800(500 \mathrm{ppb})$ & $132 \mathrm{~s}$ & $50 \mathrm{~s}$ & [36] \\
\hline
\end{tabular}

A brief evaluation of the recovery and response times for the different types of sensors evaluated in this work and a comparison with other types of sensors that are exposed to different concentrations of ammonia are shown in Table 1. The results we present in this work show that the printed hybrid SWCNT@SnO 2 are promising candidates for the fast detection of $\mathrm{NH}_{3}$ at room temperature.

Therefore, the approach presented here, combining special materials in the form of carbon nanotube-based nanocomposites and the designed polymer absorbers for the laser- 
based printing, combined with an advanced laser direct-write approach is very attractive to advance the state-of-the-art in sensing devices.

\section{Conclusions}

In summary, we successfully demonstrated the solvent-free fabrication of ${\mathrm{SWCNT} @ \mathrm{SnO}_{2}}_{2}$ nanocomposite-based sensors. The hybrid SWCNT@SnO ${ }_{2}$ nanocomposites were laser printed with high resolution onto specific metallic geometries designed onto glass substrates. The resulting sensors are reproducible and were tested against different concentrations of $\mathrm{NH}_{3}$. Upon $\mathrm{NH}_{3}$ testing (at room temperature), the $\mathrm{SWCNT@SnO} \mathrm{O}_{2}$ sensors exhibit a fast and reversible response over multiple cycles and have a theoretical detection limit in the low ppt range (i.e., $24 \mathrm{ppt}$ ). In perspective, this study provides an opportunity to fabricate sensors by a simple technique, compatible with a scale-up process, for monitoring sub-ppm ammonia concentrations. The fast response and recovery times, together with the low detection limit required for realistic monitoring of ammonia concentrations, are achieved. Thus, the implementation of SWCNT@SnO ${ }_{2}$ laser-printed sensors that can provide reliable monitoring of $\mathrm{NH}_{3}$ represent the basis for future advanced sensing devices.

Supplementary Materials: The following are available online at https://www.mdpi.com/article/10 $.3390 /$ nano11102604/s1, Figure S1: The calculation of the theoretical detection limit.

Author Contributions: Conceptualization, A.P.-P.; methodology, A.P.-P., A.F.B., and M.F.; formal analysis, A.P.-P., A.F.B., M.F., and S.I.V.; data curation, A.F.B., M.F., S.I.V., T.L., and A.P.-P.; writingoriginal draft preparation, A.F.B., M.F., S.I.V., T.L., and A.P.-P.; writing-review and editing, S.I.V., A.P.-P., and T.L.; project administration, S.I.V., T.L., and A.P.-P.; funding acquisition, A.P.-P., S.I.V., and T.L. All authors have read and agreed to the published version of the manuscript.

Funding: This work was supported by grants of the Romanian Ministry of Education and Research, CNCS-UEFISCDI, Project Number PN-III-P1-1.1-TE-2016-1417 and PN-III-P2-2.1-PED-2019-1603 "Surface acoustic wave biosensor based on functionalized graphene with monoclonal anti-alphafetoprotein antibody for hepatic cancer diagnostic" within PNCDI III, the Romanian National Nucleus Program LAPLAS VI-contract no. 16N/2019, and the Paul Scherrer Institute in Switzerland.

Institutional Review Board Statement: Not applicable.

Informed Consent Statement: Not applicable.

Data Availability Statement: The data used to support the findings of this study are available from the corresponding author upon request.

Acknowledgments: The authors would like to thank Ulrike and Alain Grisel for providing the sensor-like pads.

Conflicts of Interest: The authors declare no conflict of interest.

\section{References}

1. Guo, H.; Gu, X.; Ma, G.; Shi, S.; Wang, W.; Zuo, X.; Zhang, X. Spatial and Temporal Variations of Air Quality and Six Air Pollutants in China during 2015-2017. Sci. Rep. 2019, 9, 15201. [CrossRef]

2. Hao, J.-N.; Yan, B. Simultaneous Determination of Indoor Ammonia Pollution and Its Biological Metabolite in the Human Body with a Recyclable Nanocrystalline Lanthanide-Functionalized MOF. Nanoscale 2016, 8, 2881-2886. [CrossRef] [PubMed]

3. Wu, H.; Ma, Z.; Lin, Z.; Song, H.; Yan, S.; Shi, Y. High-Sensitive Ammonia Sensors Based on Tin Monoxide Nanoshells. Nanomaterials 2019, 9, 388. [CrossRef] [PubMed]

4. Du, H.; Li, X.; Yao, P.; Wang, J.; Sun, Y.; Dong, L. Zinc Oxide Coated Tin Oxide Nanofibers for Improved Selective Acetone Sensing. Nanomaterials 2018, 8, 509. [CrossRef] [PubMed]

5. Palla Papavlu, A.; Mattle, T.; Temmel, S.; Lehmann, U.; Hintennach, A.; Grisel, A.; Wokaun, A.; Lippert, T. Highly Sensitive SnO2 Sensor via Reactive Laser-Induced Transfer. Sci. Rep. 2016, 6, 25144. [CrossRef]

6. Kong, J.; Franklin, N.R.; Zhou, C.; Chapline, M.G.; Peng, S.; Cho, K.; Dai, H. Nanotube Molecular Wires as Chemical Sensors. Science 2000, 287, 622-625. [CrossRef]

7. Rigoni, F.; Tognolini, S.; Borghetti, P.; Drera, G.; Pagliara, S.; Goldoni, A.; Sangaletti, L. Enhancing the Sensitivity of Chemiresistor Gas Sensors Based on Pristine Carbon Nanotubes to Detect Low-Ppb Ammonia Concentrations in the Environment. Analyst 2013, 138, 7392-7399. [CrossRef] [PubMed] 
8. $\quad$ Lee, D.-J.; Choi, S.-W.; Byun, Y.T. Room Temperature Monitoring of Hydrogen Peroxide Vapor Using Platinum NanoparticlesDecorated Single-Walled Carbon Nanotube Networks. Sens. Actuators B Chem. 2018, 256, 744-750. [CrossRef]

9. Ammu, S.; Dua, V.; Agnihotra, S.R.; Surwade, S.P.; Phulgirkar, A.; Patel, S.; Manohar, S.K. Flexible, All-Organic Chemiresistor for Detecting Chemically Aggressive Vapors. J. Am. Chem. Soc. 2012, 134, 4553-4556. [CrossRef]

10. Wei, L.; Lu, D.; Wang, J.; Wei, H.; Zhao, J.; Geng, H.; Zhang, Y. Highly Sensitive Detection of Trinitrotoluene in Water by Chemiresistive Sensor Based on Noncovalently Amino Functionalized Single-Walled Carbon Nanotube. Sens. Actuator B Chem. 2014, 190, 529-534. [CrossRef]

11. Fennell, J.; Hamaguchi, H.; Yoon, B.; Swager, T. Chemiresistor Devices for Chemical Warfare Agent Detection Based on Polymer Wrapped Single-Walled Carbon Nanotubes. Sensors 2017, 17, 982. [CrossRef]

12. Pitroda, J.; Jethwa, B.; Dave, D.S.K. A Critical Review on Carbon Nanotubes. Int. J. Constr. Res. Civ. Eng. 2016, 2, 36-42. [CrossRef]

13. Schroeder, V.; Savagatrup, S.; He, M.; Ling, S.; Swager, T.M. Carbon Nanotube Chemical Sensors. Chem. Rev. 2019, 119, 599-663. [CrossRef] [PubMed]

14. Jian, Y.; Hu, W.; Zhao, Z.; Cheng, P.; Haick, H.; Yao, M.; Wu, W. Gas Sensors Based on Chemi-Resistive Hybrid Functional Nanomaterials. Nano-Micro Lett. 2020, 12, 71. [CrossRef] [PubMed]

15. Serra, P.; Piqué, A. Introduction to Laser-Induced Transfer and Other Associated Processes. In Laser Printing of Functional Materials: Fundamentals \& Applications in Electronics, 3D Microfabrication and Biomedicine; John Wiley \& Sons, Ltd.: New York, NY, USA, 2018; pp. 3-16. ISBN 978-3-527-80510-5.

16. Palla-Papavlu, A.; Dinescu, M.; Wokaun, A.; Lippert, T. Laser-Induced Forward Transfer of Single-Walled Carbon Nanotubes. Appl. Phys. A 2014, 117, 371-376. [CrossRef]

17. Arutyunyan, N.R.; Komlenok, M.S.; Kononenko, T.V.; Dezhkina, M.A.; Popovich, A.F.; Konov, V.I. Printing of Single-Wall Carbon Nanotubes via Blister-Based Laser-Induced Forward Transfer. Laser Phys. 2019, 29, 026001. [CrossRef]

18. Boutopoulos, C.; Pandis, C.; Giannakopoulos, K.; Pissis, P.; Zergioti, I. Polymer/Carbon Nanotube Composite Patterns via Laser Induced Forward Transfer. Appl. Phys. Lett. 2010, 96, 041104. [CrossRef]

19. Lasserre, F.; Rosenkranz, A.; Souza Carmona, N.; Roble, M.; Ramos-Moore, E.; Diaz-Droguett, D.E.; Mücklich, F. Simultaneous Deposition of Carbon Nanotubes and Decoration with Gold-Palladium Nanoparticles by Laser-Induced Forward Transfer. Appl. Phys. A 2016, 122, 150. [CrossRef]

20. Picaud, F.; Girardet, C.; Rao, A.M. A comparative study of single- and multiwalled carbon nanotube sensitivity to ammonia. J. Appl. Phys. 2009, 125, 014315. [CrossRef]

21. Nagel, M.; Hany, R.; Lippert, T.; Molberg, M.; Nueesch, F.A.; Rentsch, D. Aryltriazene Photopolymers for UV-Laser Applications: Improved Synthesis and Photodecomposition Study. Macromol. Chem. Phys. 2007, 208, 277-286. [CrossRef]

22. Palla-Papavlu, A.; Filipescu, M.; Vizireanu, S.; Vogt, L.; Antohe, S.; Dinescu, M.; Wokaun, A.; Lippert, T. Laser-Induced Forward Transfer of Hybrid Carbon Nanostructures. Appl. Surf. Sci. 2016, 374, 312-317. [CrossRef]

23. Sun, Y.-F.; Liu, S.-B.; Meng, F.-L.; Liu, J.-Y.; Jin, Z.; Kong, L.-T.; Liu, J.-H. Metal Oxide Nanostructures and Their Gas Sensing Properties: A Review. Sensors 2012, 12, 2610-2631. [CrossRef]

24. Pargoletti, E.; Verga, S.; Chiarello, G.L.; Longhi, M.; Cerrato, G.; Giordana, A.; Cappelletti, G. Exploring SnxTi1-xO2 Solid Solutions Grown onto Graphene Oxide (GO) as Selective Toluene Gas Sensors. Nanomaterials 2020, 10, 761. [CrossRef]

25. Su, H.C.; Zhang, M.; Bosze, W.; Myung, N.V. Tin Dioxide Functionalized Single-Walled Carbon Nanotube $\left(\mathrm{SnO}_{2} / \mathrm{SWNT}\right)-\mathrm{Based}$ Ammonia Gas Sensors and Their Sensing Mechanism. J. Electrochem. Soc. 2014, 161, B283-B290. [CrossRef]

26. Kerdcharoen, T.; Wongchoosuk, C. 11-Carbon nanotube and metal oxide hybrid materials for gas sensing. In Electronic and Optical Materials, Semiconductor Gas Sensors; Woodhead Publishing Series; Jaaniso, R., Tan, O.K., Eds.; Woodhead Publishing: Cambridge, UK, 2013; pp. 386-407. ISBN 9780857092366. [CrossRef]

27. Rigoni, F.; Drera, G.; Pagliara, S.; Perghem, E.; Pintossi, C.; Goldoni, A.; Sangaletti, L. Gas Sensing at the Nanoscale: Engineering SWCNT-ITO Nano-Heterojunctions for the Selective Detection of $\mathrm{NH}_{3}$ and $\mathrm{NO}_{2}$ Target Molecules. Nanotechnology 2017, 28, 035502. [CrossRef]

28. Tonezzer, M.; Thai, N.X.; Gasperi, F.; Van Duy, N.; Biasioli, F. Quantitative Assessment of Trout Fish Spoilage with a Single Nanowire Gas Sensor in a Thermal Gradient. Nanomaterials 2021, 11, 1604. [CrossRef] [PubMed]

29. Van Hieu, N.; Thuy, L.T.B.; Chien, N.D. Highly Sensitive Thin Film NH3 Gas Sensor Operating at Room Temperature Based on $\mathrm{SnO}_{2} / \mathrm{MWCNTs}$ Composite. Sens. Actuator B Chem. 2008, 129, 888-895. [CrossRef]

30. Hoa, N.D.; Quy, N.V.; Kim, D. Nanowire Structured SnOx-SWNT Composites: High Performance Sensor for NOx Detection. Sens. Actuator B Chem. 2009, 142, 253-259. [CrossRef]

31. Choi, K.-Y.; Park, J.-S.; Park, K.-B.; Kim, H.J.; Park, H.-D.; Kim, S.-D. Low Power Micro-Gas Sensors Using Mixed SnO 2 Nanoparticles and MWCNTs to Detect $\mathrm{NO}_{2}, \mathrm{NH}_{3}$, and Xylene Gases for Ubiquitous Sensor Network Applications. Sens. Actuator B Chem. 2010, 150, 65-72. [CrossRef]

32. Barandun, G.; Soprani, M.; Naficy, S.; Grell, M.; Kasimatis, M.; Chiu, K.L.; Ponzoni, A.; Güder, F. Cellulose Fibers Enable Near-Zero-Cost Electrical Sensing of WaterSoluble Gases. ACS Sens. 2019, 4, 1662-1669. [CrossRef]

33. Shahabuddina, M.; Sharmaa, A.; Kumar, J.; Tomar, M.; Umar, A.; Gupta, V. Metal clusters activated $\mathrm{SnO}_{2}$ thin film for low level detection of $\mathrm{NH}_{3}$ gas. Sens. Actuators B 2014, 194, 410-418. [CrossRef]

34. Li, Z.; Lin, Z.; Wang, N.; Wang, J.; Liu, W.; Sun, K.; Fuc, Y.Q.; Wang, Z. High precision $\mathrm{NH}_{3}$ sensing using network nano-sheet $\mathrm{Co}_{3} \mathrm{O}_{4}$ arrays based sensor at room temperature. Sens. Actuators B 2016, 235, 222-231. [CrossRef] 
35. Tai, H.; Duan, Z.; He, Z.; Li, X.; Xu, J.; Liu, B.; Jiang, Y. Enhanced ammonia response of Ti3C2Tx nanosheets supported by TiO 2 nanoparticles at room temperature. Sens. Actuators B Chem. 2019, 298, 126874. [CrossRef]

36. Güntner, A.T.; Wied, M.; Pineau, N.J.; Pratsinis, S.E. Rapid and Selective $\mathrm{NH}_{3}$ Sensing by Porous CuBr. Adv. Sci. 2020, 7, 1903390. [CrossRef] [PubMed] 